\title{
AV futures or futures with AVs? Bridging sociotechnical imaginaries and a multi-level perspective of autonomous vehicle visualisations in praxis
}

Robert Martin (10) ${ }^{1 凶}$

Current depictions of autonomous vehicle (AV) futures are produced primarily by automobile manufacturers that largely reflect and reinforce existing sociotechnical systems in a 'business as usual' model that frames this technology within a narrative of crisis and technological salvation. This article argues for a more complex analysis of AV futures in which images are understood as vessels for sociotechnical imaginaries that direct and delimit what we think is possible in the future. Through an analytical framework incorporating automobility, transitions, and imaginaries, I explore how depictions of AVs frame the technology as responding to various system pressures over time through a comparative analysis of two actors. The analysis suggests that regime actors deploy visual discursive material as a tool of regime stability or change to benefit their own agendas. The intention of the article is not to anticipate current trajectories but is a methodological exploration of how policymakers and planners can interpret $\mathrm{AV}$ visualisations. Therefore, the paper concludes with a discussion of the implications of these imaginaries for future transportation systems. It further suggests that policymakers and planners need to take a more active role in the development of $\mathrm{AV}$ futures by paying much more attention to the latent meanings behind $A V$ visualisations and working collaboratively with those who produce them.

\footnotetext{
${ }^{1}$ Aalborg University, Copenhagen, Denmark. ${ }^{凶}$ email: rjmart@plan.aau.dk
} 


\section{Introduction}

$\mathrm{p}$ to the present, academic discourses surrounding Autonomous Vehicles (AVs) futures have focused on safety, privacy, and accountability (Bonnefon et al., 2020), travel behaviour and land use (Soteropoulos et al., 2019), as well as road capacity, fuel efficiency, and emission reduction (Milakis et al., 2017). However, as these discussions take place within the silo of academia, public narratives of AVs have primarily been produced by incumbent regime actors, such as car manufacturers. These often take the form of visual depictions that frame AVs within the same paradigm as automobiles, leading them to become a simple substitution of existing transportation systems, rather than a radical transformation. If AVs are to have the disruptive effect that proponents imagine, reducing the negative social, environmental, and economic impacts that our current mobility practices cause, then society needs to be able to discuss and depict AV futures in a more nuanced way.

New technologies such as AVs do not appear 'out of nowhere'-their development is entangled within complex sociotechnical systems (Fraedrich et al., 2015). This new technology will be implemented after being formed from the imaginaries of a variety of system actors. Alternative AV imaginaries also exist, utilising discrete innovation pathways to conceive of AVs not as part of existing transportation systems but as components within new sustainable constellations. Therefore, society should avoid deterministic assumptions as to whether or how AVs will shape future cities, and instead focus on the plurality of imaginaries that currently exist to unpack why and how we want this technology to be a part of our lives.

Although AVs are a transportation technology that has dominated news headlines throughout the past decade, the idea is almost 75 years old (Kornhauser, 2013). From an engineering perspective, the vision of AVs is an arrangement of technologies whose aim is to replace some or all of a driver's actions and responsibilities (Lamon et al., 2006). Early visions of the technology required to achieve this task involved the integration of equally smart cars and highway systems (Wetmore, 2003). However, with the advent of machine learning, $\mathrm{AVs}$ are now seen as independent artefacts, able to navigate environments through a multitude of sensors, and computer processing power. AVs "see" the world through different data points that include GPS coordinates, radio waves, light detection, and sound to build up comprehensive representations of the vehicle and its surroundings. Developers of AV technology claim that their detection systems "can 'see' a vehicle's environment even better than human eyesight" (Burke, 2019). However, others have pointed out that there will always be an ontological gap between the world as it is, and the world as modelled by a computer vision system (Cheney-Lippold, 2019).

From a socio-technical perspective, visions of AVs typically lie outside of the artefact, critiquing existing forms of transport, addressing social needs, and solving many of the issues associated with traditional cars (Blyth et al., 2016). These visions of AVs have become a magic bullet for issues such as traffic deaths and injuries, pollution, congestion, and even climate change (Taiebat et al., 2018). So alluring has the promise of AVs become, that their role is not only imagined in relation to transport but also in terms of national economic development, security and global leadership (Mladenović et al., 2020). However, these promises assume that AV technology is advanced and well-integrated and ignore the transition period until that point and ignore possible unintended consequences such as intensifying traffic volume, urban sprawl, and increasing inequality between the haves and have-nots (Cohen and Cavoli, 2019).

The nomenclature surrounding the technology is mixed. Common terms, including driverless cars, self-driving vehicles, autonomous vehicles, and connected and autonomous vehicles are more prevalent in public forums (Cavoli et al., 2017). The term "automated vehicles" appears more in technical documents, such as the SAE Levels of Driving Automation (SAE International, 2018), which is the benchmark for AV technology categorisation. Each term appears to serve some visions of autonomy and disempowers others. For example, many AV developers utilise the SAE taxonomy to describe their system's limitations legally, while at the same time advertising the vehicle as "fully self-driving" instead of "automated" to boost the public's and policy regulators' perception of its capabilities (Stilgoe, 2017).

The development of the SAE Levels represents a vision of autonomy in which driving tasks are delegated between humans and machines by engineering standards. They range from zero assistance (Level 0) to full and unconditional automation (Level 5). The SAE Levels have contributed to a public narrative in which automation increases linearly, gradually removing human involvement and responsibility (Stayton and Stilgoe, 2020). However, Ganesh (2020) has found that rather than replacing human involvement, automation merely displaces it. Within autonomy, humans are designated micro-jobs to observe the machine and take responsibility. This can take the form of the passenger having to take control at a moment's notice or remote workers in developing countries teleoperating the machine from afar. This handover between machine and human creates murky legal responsibilities where the user is held accountable if there is an accident (Pattinson et al., 2020), and questions the very premise that this technology can ever truly be autonomous.

Within the SAE taxonomy, Levels 4 and 5 are the only vehicles to be considered to have the full self-driving capability. The difference between these two levels is the environment in which the vehicle is expected to operate. While Level 4 has limitations on the environment and will only operate if certain conditions are met, a Level 5 system is expected to perform "under all conditions". Although Level 5 may be the future of AVs that the public mostly anticipates, it remains an unattainable end goal (Stayton and Stilgoe, 2020). The underlying technology of autonomy, machine learning, requires the tight identification of tasks and problem definitions in order for it to be 'solvable' (Stilgoe, 2018). Consequently, all AV systems will need to operate within some form of constraint. By accepting this limitation, and only operating at Level 4 within Operational Design Domains, AV companies are having to rethink where they are deploying AVs and why. However, there is a marked difference in the approach that different companies take. On the one hand, companies such as Waymo are acknowledging AVs' limitations in dealing with spatial complexity and choosing to deploy their autonomous service in contextually suitable Phoenix, Arizona, because of the city's easily navigable gridlike structure and temperate climate. While on the other, companies such as Volvo and Tesla, problematise the outside world as something to be forged in a way that is best suited to autonomous driving (Sage, 2016; Stilgoe, 2017).

The idea for this paper came from a reflection on the results of a year-long research project that I completed while working as an architect for the Danish architecture studio JAJA Architects. The project investigated how AV integration may enable the transition towards sustainable transportation systems within the Copenhagen region. The output of the project was three scenarios depicting different AV futures, each illustrated through a series of diagrams, drawings, and visualisations of moments. The project was presented to a range of audiences, including academics, policymakers, and the general public, in various formats. Of the different mediums, the visualisations became the focal point of most discussions. Hajer and Versteeg (2019) describe this phenomenon as a discourse of experiencing the alternative, in which 'far from my bed'-type issues such as climate change can be addressed by presenting an 
alternative rather than through cognitive persuasion. In other words, the visualisations provided a way for the audience to discuss a vision of AVs that was embedded with concrete materialities with which they could connect to their everyday life.

Based on these experiences, the purpose of this paper is to discuss different $\mathrm{AVs}$ visualisations, considering their embeddedness within a sociotechnical system, to understand their consequences for the future of transport systems and mobility. By providing an understanding of $\mathrm{AV}$ visualisations based on imaginaries, aspects that enable or constrain transitions to sustainable transportation systems in the future can be identified. The paper begins by outlining my analytical framework, which synthesises concepts of a system of automobility, elaborated through a multi-level perspective (MLP) of transportation transitions, and sociotechnical imaginaries into an automobility-imaginaries-transitions triad. In this context, I explore how depictions of AV systems frame the technology within competing sociotechnical imaginaries that respond to various system pressures through a comparative analysis of $\mathrm{AV}$ futures from the German automobile company The Daimler Group and the Danish architecture studio JAJA Architects. Based on these considerations, I discuss these depictions and their implications for future sustainable transportation systems and then provide conclusions and an outlook regarding the need for and lines of future enquiry in the field.

\section{Analytical framework}

The system of automobility. To develop my analytical framework, I first establish my understanding of AVs as an emergent technological phenomenon within the system of automobility. The system of automobility is a concept used to understand the roots of the twentieth-century car system and how the social, economic, and commuting practices afforded by the car established and exerted self-expanding domination across the globe (Urry, 2005). Established at the end of the nineteenth century, the system immediately offered great social and economic opportunities. The effectiveness of the system did not merely come from the replacement of existing modes such as horse-drawn carriages, bicycles, or public transport, but through new forms of movement (Adams, 1999; Vigar, 2013). Car journeys became a new type of mobility, where flexibility and speed vastly expanded physical proximity and thereby encouraging latent travel demand (Stradling et al., 2000).

However, these opportunities were limited by the infrastructure available for cars. Governments reacted by extending administrative powers and expanding car infrastructure, spatially and temporally splintering urban territories into districts of home, work, and leisure in the pursuit of further economic gain (Freudendal-Pedersen et al., 2016). The ensuing mass production of the car made freedom and independence available to the many, and as more and more sought to take advantage, the car became cherished as a prized possession that embodied status and cultural significance (Sheller, 2004; Mom, 2014).

Throughout the twentieth century, the system of automobility took hold, and those ambitions of independence turned into dependence (Goodwin, 1995). Car use was no longer seen as a comfort but as a necessity for economic and social participation (Lyons, 2015). Society became forced to tolerate the consequences of mass car ownership and car use in the form of parked cars dominating the streets of urban centres, congestion and traffic jams, health-threatening pollution, and the financial burden of car maintenance (ibid.). Despite these negative consequences, the dominance of the system has been continually supported and reinforced by a perceived correlation between economic growth and car use (Mackinnon et al., 2008). Global economies became tied to not only the movement of people but also the car's greater ecosystem of resource extraction, supply chains, manufacturing, sales, and infrastructure construction. To foster economic growth, policymakers ignored the negative externalities and physically and socially reconstructed cities in favour of the car (Norton, 2010). In spatial terms, the system of automobility became, quite literally, cemented into our cities' structures through a vast array of material infrastructures including street profiles, highways, parking garages, petrol stations, and urban layouts (Zijlstra and Avelino, 2012).

To summarise, a central premise of my understanding of AVs is that technology is an emerging phenomenon within a sociotechnical system in which our global economies, planning policies, cityscapes, and everyday livelihoods are entangled, all around a practice of privately-owned car use. Furthermore, the system of automobility has become so ingrained in our societies that it dominates our present and future understanding of the urban (Hajer and Versteeg, 2019). One must only look at any recent blockbuster film set in a future utopian or dystopian landscape to see the prevalence of the car, in some form or another, in our understanding of what is to come. Depictions of AV futures cannot escape this: Any discussion of AV imaginaries takes place within the framework of cars, set as either a reaction or compliment to them. Therefore, the system of automobility is used as one of the lenses for the interpretation of AV imaginaries because its legacy implies that a transition will require systems-level rethinking, rather than focus on the $\mathrm{AV}$ as an individual object.

A multi-level perspective of the system of automobility. While the system of automobility may appear irreplaceable, discussions surrounding climate change, urbanisation, and road safety have highlighted the need for a transition to a new transportation system (Köhler et al., 2019). Geels (2012) introduced the MLP as a framework to understand transitions in complex sociotechnical systems that offer analytical insight into how AVs may enable such a transition. The MLP differs from other cause-andeffect-type processes by describing transitions not as a result of one single driver, but as the 'result of the interplay of multiple developments at three analytical levels' (Geels, 2012, p. 472). The three analytical levels, which refer to diverse constellations of increasingly hierarchical stability, are sociotechnical landscapes (the uppermost level and the context that frames both niche and regime dynamics), sociotechnical regimes (established practices and rules that enable and constrain various incumbent actors, that reproduce existing systems, and that are barriers to change), and niche innovations (radical innovations that deviate from existing regimes that may be either adopted by the regime or replace it). Figure 1 shows an exemplary representation of the levels, visually showcasing analytical elements of the system of automobility without displaying the dynamic processes between them (see Moradi and Vagnoni, 2018, for a more comprehensive analysis of the system of automobility using the MLP).

An MLP on the system of automobility displays an entangled sociotechnical system arranged around a dominant automobility regime (Geels, 2012). The regime is currently facing destabilising forces from landscape pressures such as climate change debates, urbanisation, road traffic deaths, and pollution, as well as emerging niche innovations such as AVs, micromobility devices, the sharing economy enabled through the diffusion of information and communications technology (ICT), and 'car-free' traffic planning. The regime is resisting these forces through instrumental, discursive, and institutional forms of power (Geels, 2014). These include governmental strategies to support automobile industries, exploitation of the cultural associations of the car with freedom, and induced demand for mobility. Some authors have also suggested that the automobility regime faces pressures from competing subaltern regimes such as rail, bus, and cycling (Hodson et al., 2015; Turnheim et al., 2015). 

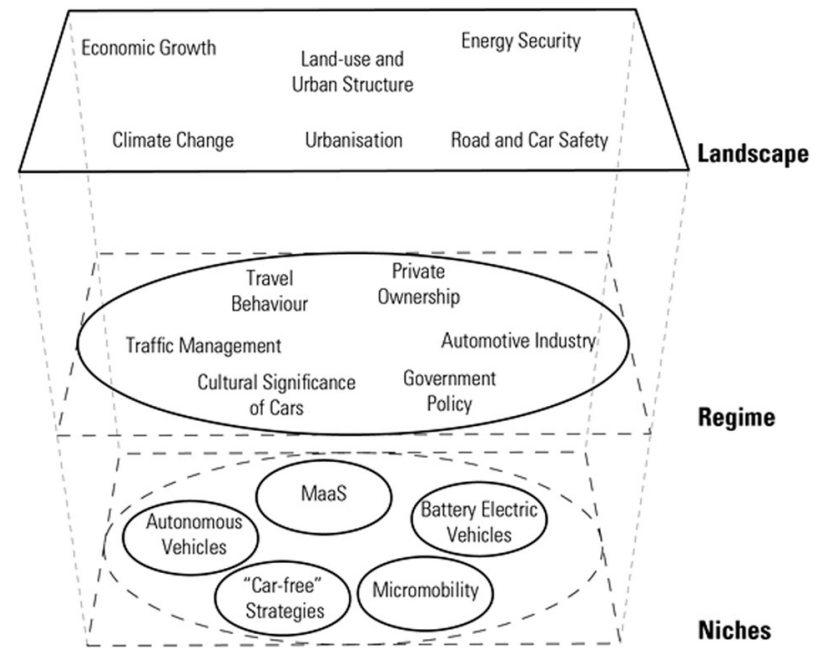

Fig. 1 An exemplary representation of the system of automobility using the MLP.

The analytical framework of the MLP is a particularly helpful approach when focusing on how new technologies, such as AVs, enter sociotechnical systems through the 'niche' level. They do so through a long-term view on the co-evolution of technology and society involving multiple dimensions (industry lobby groups, consumer preferences, governmental policy, infrastructure, and spatial arrangements, and cultural values), as well as considering the interactions among different groups of stakeholders. It demonstrates how new technologies, such as AVs, never enter sociotechnical systems alone, but rather are formed by the complex interactions among social groups, various actors, and landscape pressures. Importantly, the MLP covers, on the one hand, how the automobility regime may exploit AVs to stabilise its own position in the system through lock-in measures and resistance to change, and how other system actors deploy them to replace the regime, on the other hand.

Sociotechnical imaginaries as drivers of transitions. Having grounded my analytical perspective in the understanding of AVs as an emerging niche innovation within an entangled sociotechnical system arranged around a dominant automobility regime, I turn to how sociotechnical imaginaries work as drivers of transitions. Transitions may occur through interactions between the different levels of the MLP. The nature of these interactions can be described as transition pathways (Geels and Schot, 2010). Transition pathways detail how niche innovations are developed over time by various social actors and how they contribute to replacing current regimes or stabilising incumbents. Generally, the dynamics that create transitions are that niche innovations build up internal momentum, changes at the landscape level generate pressure on the regime, and the destabilisation of the regime makes a window of opportunity for niche technologies to emerge (ibid.). However, the nature of the transition, and whether it moves towards a more sustainable system, depends on the timing and nature of the interaction among the different levels and the actors that drive the interaction.

Different entry points exist to understand this interrelation. Sociotechnical imaginaries (Jasanoff, 2015) offer one such explanation by illustrating 'the myriad of ways in which scientific and technological visions enter into the assemblages of materiality, meaning, and morality that constitute robust forms of social life' (Jasanoff, 2015, p. 4). Bridging the imaginary and the material, the concept of sociotechnical imaginaries is crucial in understanding how AVs are made and why. Sociotechnical imaginaries also allow us to understand technology in terms of storytelling, visualisation, and imagining, as these are the mediums in which new technologies are developed, stabilised, and propagated by different social groups and actors ( $\mathrm{McNeil}$ et al., 2017). For example, Sadowski and Bendor (2018) have argued that large ICT companies utilise sociotechnical imaginaries to create a vision that presents the 'Smart City' within a narrative of crisis and technological salvation from the services that it offers. The authors have further claimed that these companies use this tool for 'directing and delimiting what we can imagine as possible' (2018, p. 5) to suit their corporate agenda and crowd out alternative visions for the future. Often, multiple imaginaries co-exist simultaneously, with actors competing for the dominant sociotechnical imaginary and, therefore, the basis on how the technology will eventually be used (Jasanoff, 2015).

Combining the above concepts into an automobilityimaginaries-transitions triad enables a deeper understanding of how depictions of AV futures are framed, developed, and deployed. By synthesising these concepts into a single analytical framework, I am better able to analyse the discursive meanings found in AV depictions by setting them alongside the broader context of automobility, landscape pressures, parallel niche innovations. Furthermore, this framework provides both a temporal and spatial overview of how these imaginaries change over time. Therefore, the AV depiction is not understood as a future, but as a figurative Band-Aid deployed to preserve existing regime constellations.

The next section explains the empirical evidence that I use within this framework to understand the consequences of $\mathrm{AV}$ imaginaries for the future of the transport system and mobility.

\section{Methodology: a visual discourse analysis of two competing sociotechnical imaginaries}

This analysis is based on two data sets of visualisations from competing system actors regarding the role of AVs within a future transportation system. The first set of data is visual material from the German multinational automotive corporation Daimler. The material was collected from Daimler's Global Media website using the search term 'autonomous vehicle' within the date range 2015-2019 to see how the company's sociotechnical imaginary has evolved over time. Although the company had previously advertised vehicles with autonomous features to assist driving, this period marks when Daimler advertised fully autonomous vehicles. The search request returned 445 images associated with Daimler's press releases. Three images were selected based on their depiction of AVs within a future urban environment. The rest were discarded because they represented event pictures, exterior and interior design, safety features, and charts.

The second set of data is visual material collected from a sixmonth research project conducted in 2017-2018 called Copenhagen 2050 (CPH2050), which looked into the spatial implications of AVs via scenario planning methods. The project was funded by the Danish Arts Foundation and was a collaboration between JAJA Architects and the engineering consultancy firm NIRAS. The visual material used for the data was produced at JAJA, where I was working as an architect at that time. The visualisations were based on inputs from transport planners, employees from local municipalities, representatives of public transport authorities, architects, landscape architects, and users. In total, nine visualisations were produced throughout the project. The data used in this article is a selection of three visualisations, which were chosen because AVs were depicted in part of the image.

After gathering the material, I analysed each image using visual discourse analysis (VDA; (Albers, 2013). VDA can unfold how images are used as a medium to construct and disseminate sociotechnical imaginaries. The method is based on semiotics 
(Hodge and Kress, 1988), discourse analysis (Gee, 2006), and the grammar of visual design (Kress and van Leeuwen, 2006) and is concerned with studying the structures and conventions within visual texts to identify how certain social norms are created in their production. Sociotechnical imaginaries 'reside in the reservoir of norms and discourses, metaphors and cultural meanings' (Jasanoff and Kim, 2009, p. 123), and VDA was therefore used to trace how individual images work within broader systems of meaning to uncover the underlying approach to AV development of each company. Within VDA, three modalities can contribute to a critical understanding of an image: (1) technological, which involves the various physical apparatuses used to create and view the image; (2) compositional, which references the formal structures of the image and compositional elements that denote visual content; and (3) social, which connotates social and political ideologies (Rose, 2010). As this study was not concerned with the apparatus employed to produce the image, the research only focused on the compositional and social modalities of the image through the use of semiology (Jewitt and Oyama, 2011) and compositional interpretation (Rose, 2010, p. 35).

By interpreting images through both a semiotic and compositional lens, I am able to explore how system actors attempt to engage with system pressures within their presentation of AVs, as well as their perceived hierarchy of system elements that may reinforce or destabilise an existing regime. Through semiotic analysis, a coding scheme was established that identified the individual elements within each image as 'first-order signs', or what was being depicted in a denotative sense. A second coding scheme was produced by relating the 'second-order signifiers, or what values the signs express, to themes identified in the niche and landscape levels of the MLP. Alternatively, compositional interpretation ignores symbolic representation and mostly examines the composition of the physical world itself. Compositional analysis scrutinises images' content, colour, spatial organisation, and focalisers to understand the significance of the images.

The following tables (Tables 1 and 2) display a limited selection of results from the semiotic and compositional analysis. Both methods produced far more results, but for clarity and efficiency, only results that were used further in the discussion are included. Together, these tables provide a temporal and spatial overview of the landscape of automobility, system pressures, and parallel niche innovations, as well as how actors construct their imaginaries through them.

\section{Competing visions for future transport systems}

In analysing the visualisations produced by Daimler and JAJA, I identified that they are not only instances of marketing material or research outputs: They also present frameworks for the future that the companies want to create. Both companies offer a narrative about the salvation of cities through AVs that aligns itself with ongoing landscape discourses. Although there are strong similarities between the stories presented by the two companies, I found clear differences in the preferential treatment of certain systems over others, how signs relating to different sociotechnical elements are deployed, and the way in which each company's depictions present either regime stabilisation or replacement. These narratives, their relationship to landscape pressures, and their different utilisation of AVs are described below, as are their consequences for future transport systems and mobility.

\section{AV futures from the incumbent, Daimler}

Responding to landscape discourses. Publicly, the general stated motivation to pursue AVs is to improve road safety. This coincides with the landscape pressure and cultural reaction to the physical harm that the system of automobility imposes on societies around the world. Globally, road traffic accidents cause approximately 1.35 million deaths each year and are the leading cause of death among young people (World Health Organization, 2018). Similarly to 'jaywalking' campaigns of the 1930s, in which coalitions of automobility regime actors exercised their collective power to remove pedestrians from the streets in the name of road safety (Norton, 2007), incumbent regime actors are currently casting blame on the human driver as a means to accelerate $\mathrm{AV}$ development in an effort to vindicate the system of automobility itself.

While each image analysed includes signifiers connotating safety, Daimler's first presentation of an AV future (Fig. 2) presents them in a way that prioritises vehicle use. Compositionally, the image applies a traditional way in which cars are advertised: The focaliser of the image is the vehicle, which is both the central figure in the image and highlighted through a stark contrast in colour between it and the rest of the scene. Furthermore, the AV sits both physically and metaphorically separated from the rest of its environment. Traditional safety elements that would connect a human driver to the outside world, such as rear-view mirrors and transparent windows, are noticeably absent in this vehicle. Instead, the notion of safety is implied through a system of computer vision, machine learning, and sensors that have instructed the vehicle to stop and that project an illuminated pedestrian crossing that allows the man dressed in business attire to cross the road safely. In this depiction, the passenger, if there is one, is cleared of all responsibility of safely manoeuvring, with complete control being outsourced to the AV system. By removing what incumbent regime actors see as the weakest link in the system of automobility, the human element, this sociotechnical imaginary presents a future of continued automobile use devoid of road traffic accidents through the application of AV technology.

The landscape development of urbanisation also presents particular challenges to the automobility regime in Fig. 2. Throughout the twentieth century, automobile-enabled suburbanisation was seen as a way to reduce urban problems (Geels, 2005), which became the signature characteristic of the system of automobility. The continued increase in car use required an everincreasing suburban periphery, which reinforced itself by only being accessible by car. This trend is expected to be reversed in the twentyfirst-century, with projections anticipating that $68 \%$ of the global population will live in dense urban centres by 2050 (United Nations Department of Economic and Social Affairs, 2019). Density is the nemesis of the car, and society is already experiencing the consequence of this tension through traffic congestion, high parking fees, and even road closures. Figure 2 presents a paradoxical solution to this problem. The image embeds the landscape development of urbanisation through the inclusion of futuristic high-rise architecture, implying that space is at such a premium that city residents are forced to live in smaller and smaller apartments and nature is confined to the facades of buildings. However, in this densified future, road space has actually increased. Physical road features such as pedestrian crossings, sidewalks, and road markings are removed, expanding the domain of AVs while also granting them complete control over when other modes can use the space. For example, the crossing pedestrian depicted in this future may only safely cross the road when the AV allows it, demonstrating that the sociotechnical imaginary presented here by Daimler is one ruled by AVs.

Emerging niches used to mask regime stabilisation. The AV sociotechnical imaginaries presented by Daimler in this collected study are neither fixed nor static. Instead, they demonstrate a coevolution in line with emerging niche innovations and landscape developments to absorb these destabilising forces into their own narrative of AVs. In the period between 2015 and 2017, corresponding to the time between the release of Daimler's first and second AV depiction, several transport technologies such as 


\section{Table 1 Results of semiotic analysis.}

\section{Visualisation}

Mercedes-Benz F 015 Luxury in Motion: A virtual zebra crossing indicating to Vehicle pedestrians on the side of the road that it is safe to cross. 2015 (Fig. 2)

Future mobility: Bosch and Daimler join forces to work on a fully automated, driverless system. 2017 (Fig. 3)

Bosch and Daimler: Metropolis in California to become a pilot city for automated driving. 2018 (Fig. 4)

JAJA - CPH2050: Reconnecting the city (Fig. 5)

JAJA - CPH2050: Suburban Transformation (Fig. 6)

JAJA - CPH2050: From the train station to mobility hub (Fig. 7)

First-order sign (Denotation) Second-order signifiers (Connotation)

\section{Darkened windows \\ Missing rear-view mirrors \\ Sensor/laser \\ Pedestrian \\ Digital sidewalk \\ Contemporary architecture \\ Trees/grass on building}

Robotaxis

Single-occupant AV

AV shuttle

Parked AVs

Metro

Cyclists

Pedestrians

Delivery van

E-scooter

Urban life

Pedestrian crossing

Traffic lights

Bicycle lanes

American flag

Subway sign

Doughnut sign

Larger vehicles

Taxis become private

Missing cyclists

Palm trees

People of colour

Bicycle

Pedestrian crossing

Pedestrian

AV shuttle

Retail space

Yacht

Children

Contemporary Architecture

Traffic signal

AV shuttle

Children

Residential architecture

Solar panels

Runners

Communal dining table

Father with child

Greenhouse

Play equipment

Smartphone

Bicycle

Bicycle lane

Pedestrian crossing

Pedestrians

AV shuttle

Traveller

Commuter

Train

Trees

Real-time information screen
Luxury, futuristic, smart, traditional

Privacy, autonomy

Autonomy

Safety, trust

Safety, trust

Safety, trust

Futuristic, high density, less space

Environmental awareness, less space

Sustainability, accessibility,

mobility, future

Sustainability, privacy, future, micromobility

Sustainability, accessibility, mobility, future

Service, availability, future

Sustainability, multimodality

Sustainability, multimodality,

micromobility

Sustainability, liveability

Logistics, integrated

Sustainability, multimodality,

micromobility

Liveability

Safety

Safety

Safety, sustainability, micromobility

Nationalism

Localism

Cultural

Success, luxury, privacy

Success, luxury, privacy

Sustainability, accessibility, multimodality

Localism, culture

Multiculturalism, localism

Sustainability, multimodality

Safety

Safety, trust

Sustainable, future, technology, safety

Commercial activity, liveability

Recreation, wealth, liveability

Safety, inclusion

Future, wealth, gentrification

Safety, law enforcement

Sustainable, future, technology, safety

Safety, inclusion, community

Family, wealth, aspiration

Sustainability, self-reliance

Active lifestyles, diverse demographics

Community

Family, lifestyle, socioeconomic status

Sustainability, community, self-reliance

Community, family

Connected, technology, future

Sustainability, multimodality

Safety, sustainability

Safety

Safety, trust

Sustainable, future, technology

Accessibility, efficiency

Efficiency

Sustainability

Environmental awareness

Connected, technology,

efficiency, future 


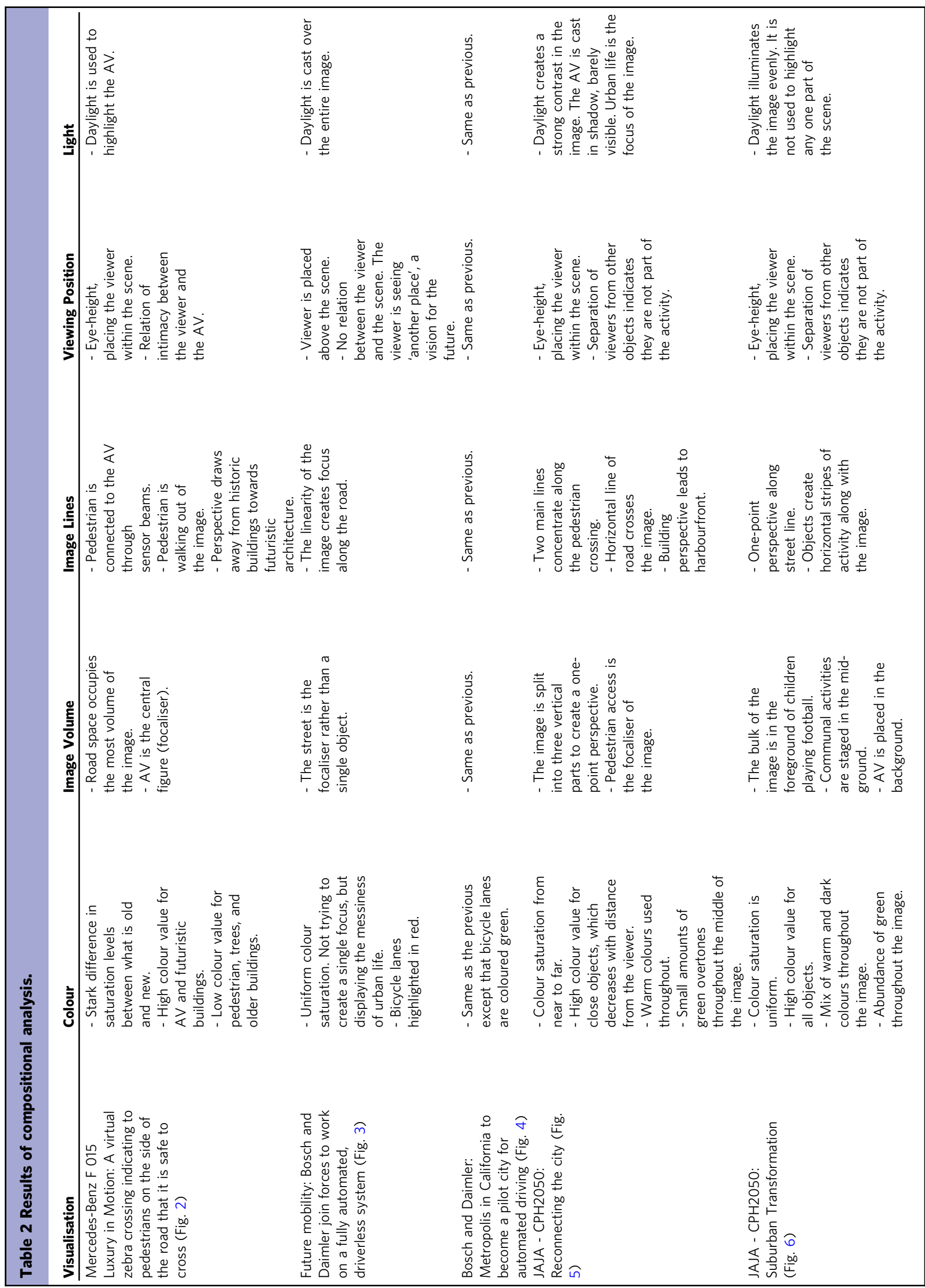




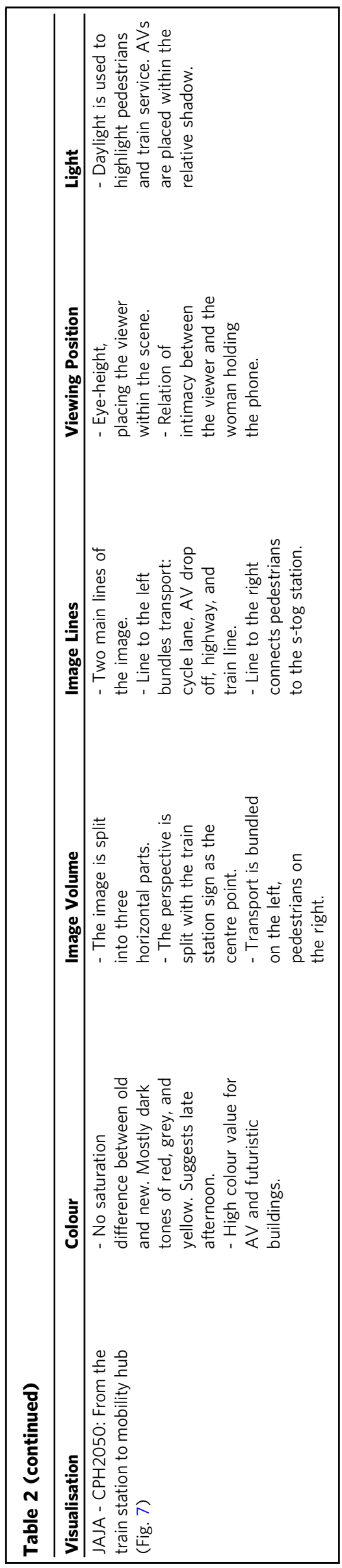

micromobility devices, Mobility as a Service, and urban multimodality have emerged and are seen by some as disrupting traditional transportation systems. These emerging technologies differ from the incumbent automobility regime, as they suggest a plurality of transport modes existing harmoniously, rather than the presence of a single dominant mode.

Demonstrating an alignment with this emerging discourse, Fig. 3 presents a sharp departure from the traditional automobile advertisement shown in Fig. 2. Rather than selling an object, Fig. 3 presents a total system of mobility that is forged around Daimler's AV system. Compositionally, this depiction is viewed from a birdeye position, showcasing the entire system within a dense urban environment of apartment dwellings, alfresco cafes, and cultural institutions with no set focal point. Instead, an array of elements are spread throughout the image that engages and contains many emerging niche innovations mixed in with traditional automobiles, implying the plurality of the system.

While the image showcases a wide range of vehicle types that include more sustainable modes such as bicycles, e-scooters, shuttle buses, and mass transit, which may indicate an environmentally sustainable transport system, it also showcases a clear hierarchy of modal preference in the way the image is constructed. For example, the bicycle lanes, which are highlighted in red, clearly preference AVs and automobiles in their design. Rather than continuing across intersections, bicycle lanes are discontinuous, always giving the right of way to AVs. Bicycle lanes are further de-prioritised in the way that they are subservient to other modes: The delivery van, with no designated parking area, is standing in the cycle lane; the AV shuttlebus is standing in one as passengers embark or disembark; and parking spaces are located adjacent to the sidewalk, rather the road, causing points of conflicts between passing cyclists and AVs. These examples showcase Daimler's ignorance of apathy towards other modes of transit.

Although signs of safety, multimodality, and sustainability appear in this depiction, a compositional analysis of the image demonstrates a preference for safety, convenience, availability, and efficiency for Daimler's AV users. Destabilising niche innovation elements are merely included in the image to mask an otherwise typical depiction of a streetscape within the system of automobility. If one were to remove these signifiers relating to emerging niche innovations, the core of this sociotechnical imaginary is a 'business as usual' approach, in which roads and parking spaces dominant the urban environment.

Translated sociotechnical imaginaries. The final AV depiction by Daimler (Fig. 4) presents a translation of its sociotechnical imaginary across regional contexts. The depiction, which is arguably identical to that in Fig. 3, simply swaps signs relating to a German context with those of a U.S. one. While the identities of both countries are intertwined with automobile production, their automobile practices and cultures have evolved along two divergent paths (Kaiserfeld, 2007). Rather than understand and depict a future that is representative of local conditions, Daimler simply superimposes a series of cultural signs relating to California on a generic futuristic landscape originally intended for a German audience. Palm trees, people of colour, a doughnut shop sign, and a U.S. flag are all simply added in an attempt to make its system palatable to a U.S. context. Furthermore, many of the changes dilute several of the environmental and health benefits in the original vision. Several cyclists are simply removed, shared robotaxis are relabelled as privately-owned vehicles, and the size of the cars is increased.

Kim (2018) has suggested that when sociotechnical imaginaries are simply transplanted from one context to another, gaps between the imaginary and practice can occur through the loss of the original meaning of the former. For example, the plurality of 


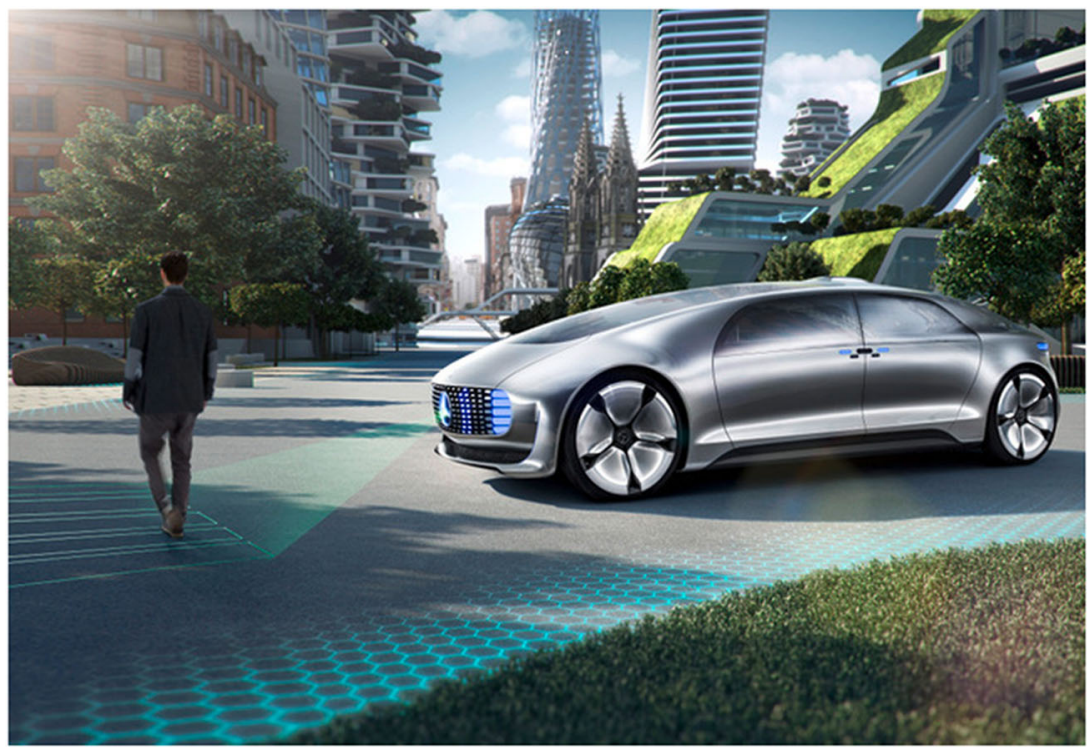

Fig. 2 Mercedes-Benz F 015 Luxury in Motion: A virtual zebra crossing indicating to pedestrians on the side of the road that it is safe to cross. This figure is not covered by the Creative Commons Attribution 4.0 International License. Reproduced with permission of Global Daimler Media; copyright (c) The Daimler Group (2015), all rights reserved.

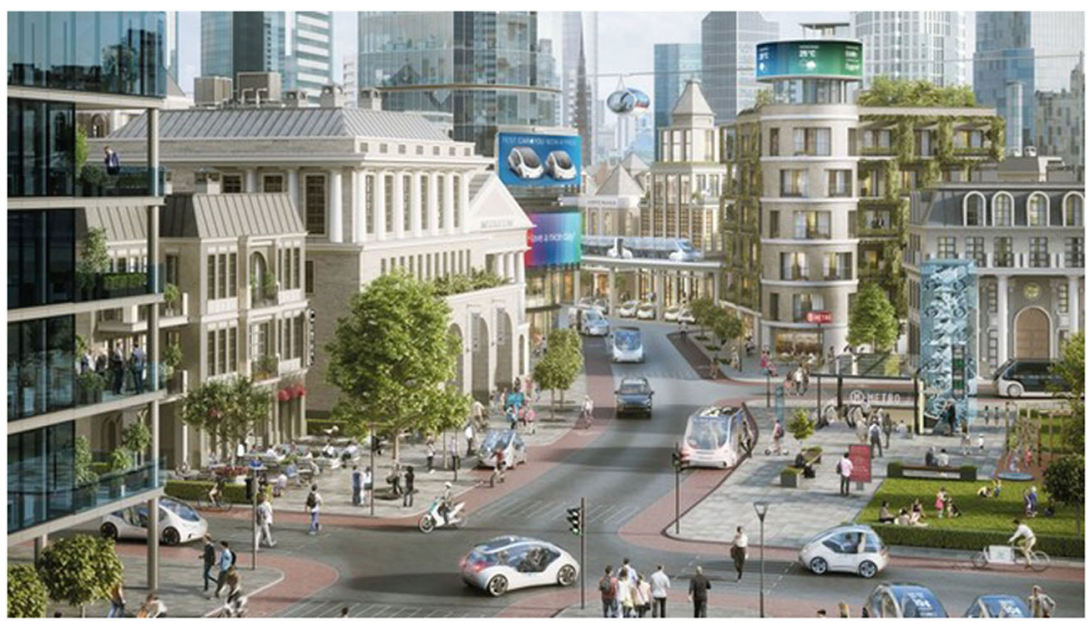

Fig. 3 Future mobility: Bosch and Daimler join forces to work on fully automated, driverless system. This figure is not covered by the Creative Commons Attribution 4.0 International License. Reproduced with permission of Global Daimler Media; copyright (c) The Daimler Group (2017)(2015)(2015), all rights reserved.

transport modes embedded in the narrative of both the original and transplanted sociotechnical imaginary presupposes a backbone of public transport infrastructure, which varies in each context. While European cities often have existing urban transit networks integrated into their urban fabric, this is rare in a U.S. context, as the country, despite outlier cities such as New York and Washington D.C., has historically had a complicated social, cultural, and political relationship to public transport (Conley, 2009). Daimler formally imitates a European streetscape as a benchmark of multimodality because this legitimises its own product as a measure of sustainability. This reflects the emphasis of the landscape pressures, such as climate change discourses, that automobile manufacturers are attempting to mitigate within their depictions of AVs. However, if this sociotechnical imaginary were to be established, the system would change in practice. To suggest that in this transplanted sociotechnical imaginary Daimler's AV system would accompany such large-scale public transit investments is well beyond its scope or desired outcome.
While some may perceive this as a car company only undermining discussions on sustainability to sell more cars, this would discard any thought regarding the coerciveness of the system of automobility. Daimler is not discussing multimodal systems because they only want to sell more cars; they're engaging with them because they see the zeitgeist shift and want to stay in business. As an incumbent regime actor, Daimler must remain fluid in order to react to landscape pressures. However, as the inconsistency in Daimler's presentation of the future indicates, the dominance of the system of automobility over their perception of the future means that they are unable to see one that does not involve the car.

\section{Futures with AVs by JAJA architects}

Sociotechnical imaginaries shaped by liveability discourses. Unlike Daimler, whose visions primarily depict a future of regime stabilisation, the visualisations from JAJA's CPH2050 project reflect 


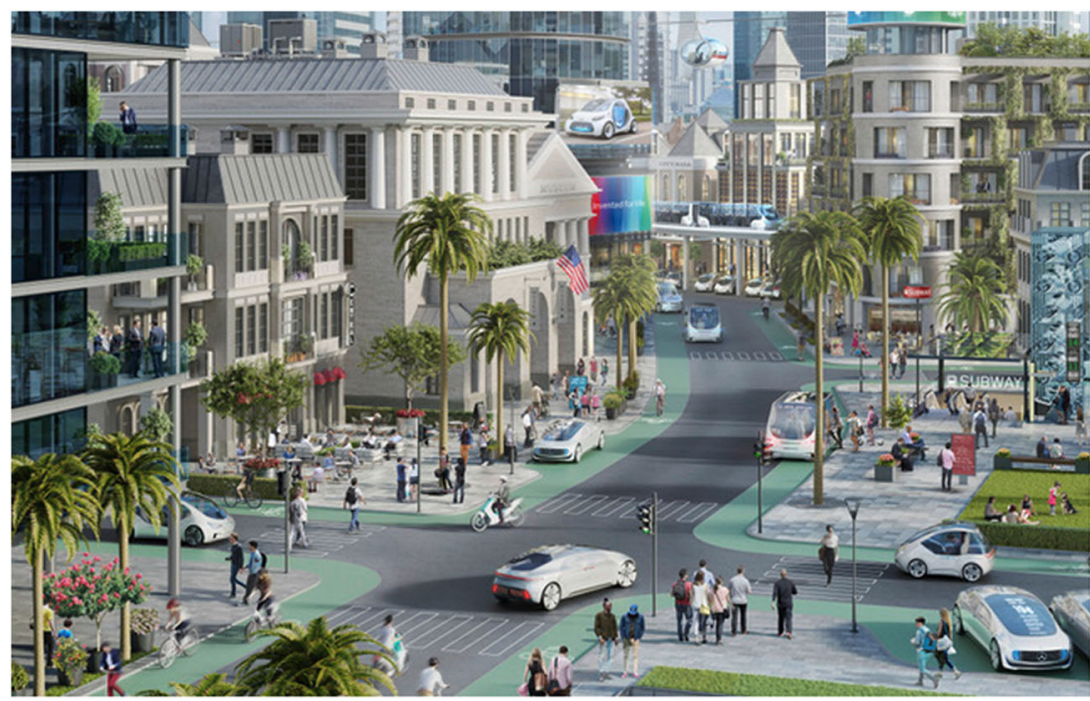

Fig. 4 Bosch and Daimler: Metropolis in California to become a pilot for automated driving. This figure is not covered by the Creative Commons Attribution 4.0 International License. Reproduced with permission of Global Daimler Media; copyright (c) The Daimler Group (2018)(2015)(2015), all rights reserved.

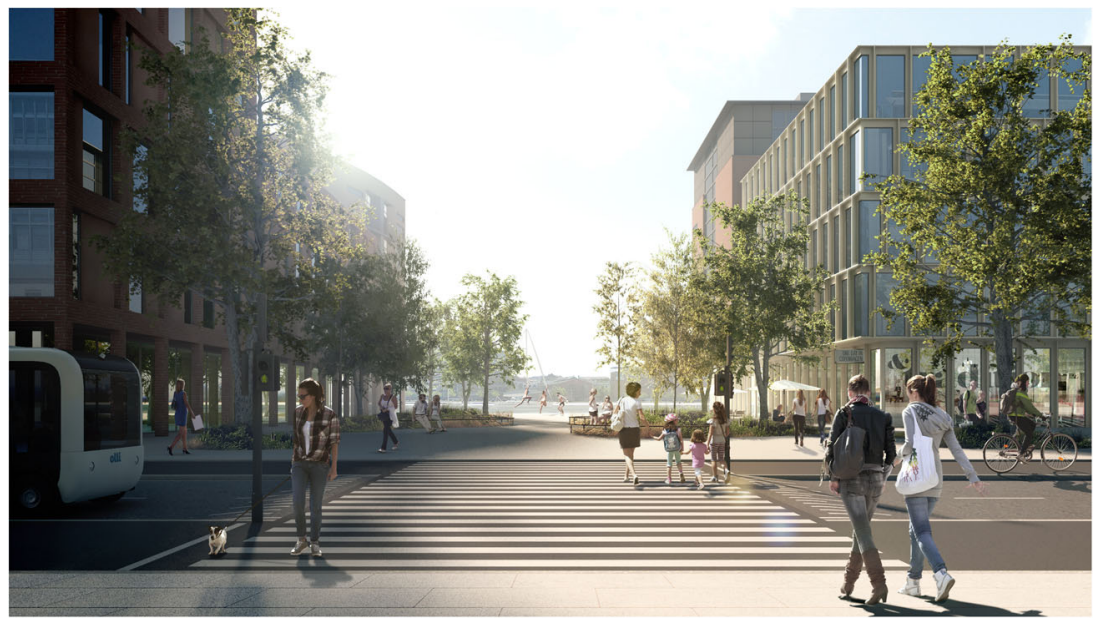

Fig. 5 CPH2050: Reconnecting the city. This figure is not covered by the Creative Commons Attribution 4.0 International License. Reproduced with permission of JAJA (2018); copyright (C) JAJA Architects, all rights reserved.

the expectations of a broad set of interests located outside the regime. These expectations represent discourses relating to the improvement of public transport, sustainability agendas, the improvement of citizens' welfare, and urban development. As a result, there is no single 'product' sold; rather, the product is a lifestyle contained within a particular form of urbanism. One can see overlapping similarities between this form of urbanism and wider landscape developments surrounding the metric of 'sustainable liveability', which has exploded over the past two decades through a series of city-ranking indices. Often, these indices tend to preference access to cultural amenities, cafes, bars, and restaurants, but they have also recently included less superficial metrics, such as housing affordability, well-functioning public transport, and access to clean water. While these rankings may seem innocent and objective, some criticise them for framing a particular expectation of what life and living in a city should be (Jacobs, 2014). Nonetheless, cities shape urban policy, strategy, and planning projects in pursuit of these rankings that draw in investment from around the world (McArthur and Robin, 2019).
Since the establishment of these indices, Copenhagen has consistently ranked as a top-tier global city, which has encouraged the city's politicians to continually chase this accolade so that it can market itself as the world's most 'liveable' city (Simpson et al., 2018). By engaging with liveability's discursive power, JAJA mobilises a counter-sociotechnical imaginary that rejects the system of automobility, reconnecting transport policy with everyday urban life. For example, instead of depicting a system of mobility, Fig. 5 illustrates a mobility lifestyle associated with economic prosperity. Compositionally, the image guides the viewer through a one-point perspective of signs relating to liveability: commercial retail outlets, citizens swimming in the harbour, shaded places to sit, coffee stands, a yacht, and bicyclesall signs of a 'good life'. The image literally casts a shadow on the single AV shown, utilising these denotations of wealth to propose the spatial, economic, and social benefits of deprioritising vehicles in urban contexts (Fig. 6).

The idea of sustainability is communicated subtly in the image through the inclusion of trees, grass, a cyclist, and a clean harbour 


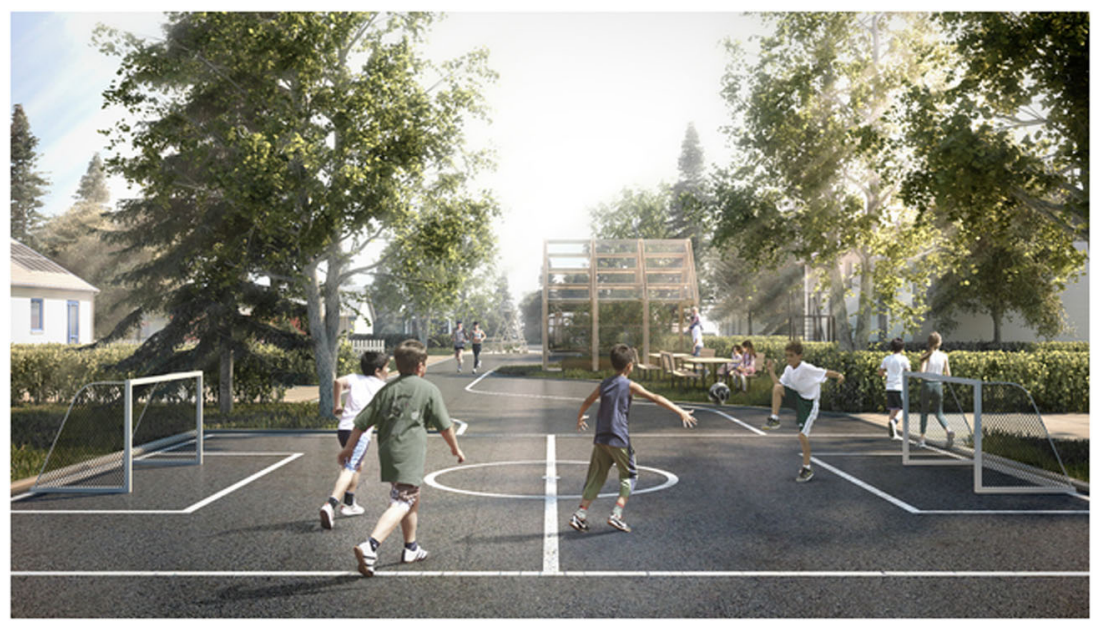

Fig. 6 CPH2050: Suburban transformation. This figure is not covered by the Creative Commons Attribution 4.0 International License. Reproduced with permission of JAJA (2018); copyright (c) JAJA Architects, all rights reserved.

fit for swimming. Furthermore, a single AV is represented as a shared shuttle waiting for pedestrians to cross. This action is enabled by the only other symbol of technology present in the image, traffic lights. Safety, therefore, is not communicated through technological systems as in Daimler's depictions, but rather through fixed spatial infrastructure and children safely crossing the street. Herein lies a continuing theme throughout each of JAJA's visualisations: The transformation of space will drive the transition towards future transportation systems.

Transforming the landscape of the automobility regime. As stated previously, suburbanisation is the physical manifestation of the system of automobility, which has locked car dependence into the landscape of transportation. Interestingly, none of Daimler's depictions of AVs engage with the environment, instead only presenting their use within dense inner-city contexts. Whether this is an oversight or a general acceptance that AVs will not change mobility practices in these areas cannot be deduced; however, as suburban areas have been so pivotal in staging our mobility practices, understanding actors' approaches in these areas is crucial to understanding their ambitions for future AV use.

JAJA's portrayal of a suburban environment (Fig. 6) provides many insights into how it views the role of AVs. First, this depiction relies on the absence of transport to communicate its vision for the future of transportation. Landscape developments, such as economic development, throughout the twentieth century, saw streets become increasingly defined as transport arteries, rather than as spaces for social activity (Geels, 2005), which JAJA's visualisation counteracts. Apart from one lone AV in the far background, vehicles are not shown in this streetscape. Instead, the focal point of the image is road infrastructure that has been re-appropriated to provide temporary play space for neighbourhood children and a track for active people to jog on.

This denotes a response to two other ongoing landscape pressures to the current automobility regime: The suburban environment that is often associated with sedentary lifestyles enabled through car use is replaced with a more active and healthier environment, and the safety of streets for pedestrians to use. Although relying on the technological application of sensors on the AV to detect and safely stop pedestrians, the typical straight suburban street has also been manipulated to slow incoming traffic.

Similar to all other examples in this analysis, this image also engages with the landscape pressure of climate change through the application of signs relating to sustainability. However, instead of only including sustainable modes of transport, this image utilises signs such as solar panels on the houses, a community greenhouse, and an abundance of trees to depict a sustainable lifestyle.

Finally, the vision also speaks to a group not often involved with the discourse on AVs-the family unit. While a quick google search of the term "autonomous vehicle" returns images of business suit-clad elites and inner-city professionals giving PowerPoint presentations in the cabins of cars, this image presents a picture of idealised family life. Instead of generic cityscapes, the image showcases residential architecture, a man carrying his young daughter, and children playing in the street, which all create a vision of a community that extends beyond the boundary of the residential plot.

Promotion of subaltern regimes. The final image analysed does not portray a particular lifestyle, but rather a clear hierarchy of modes within JAJA's imaginary (Fig. 7). This vision does not depict a new system, but a reconfiguration that promotes existing subaltern regimes such as trains, buses, and cycling, through subservient AV shuttle services. Unlike previous depictions from both companies, public transit infrastructure forms the largest volume of this image. AVs are presented in the image but are placed in the midground, behind the cyclist and train station, indicating that they are a subservient feeder to the transport system, rather than the dominant mode. Road space, as a percentage of the total image, is small, with a pedestrian crossing appearing much more prominent than the small amount of space available to AVs. Public transport is further made prominent through the vanishing point of the image, which is directed towards the arriving train in the background, highlighted by a stream of pedestrians.

Finally, the image embeds numerous elements relating to emerging niche technologies: the woman navigating using a smartphone; real-time information screens indicating departure times and connections; and AVs, both on the ground and mirrored in the screen. However, these technologies do not dominate the image and are all overlaid over existing infrastructure. These signs are arranged carefully to indicate that physical infrastructure, not technological advancements, will be what leads this sociotechnical transition and indicate which transport modes are preferred.

Implications for future transportation systems. This chapter has analysed two distinct approaches to conceiving AV futures. The goal has not been to compare Daimler to JAJA but to exemplify how actors from different system positions utilise depictions of AVs to frame the technology within competing sociotechnical imaginaries. Furthermore, the analysis shows that in the case of 


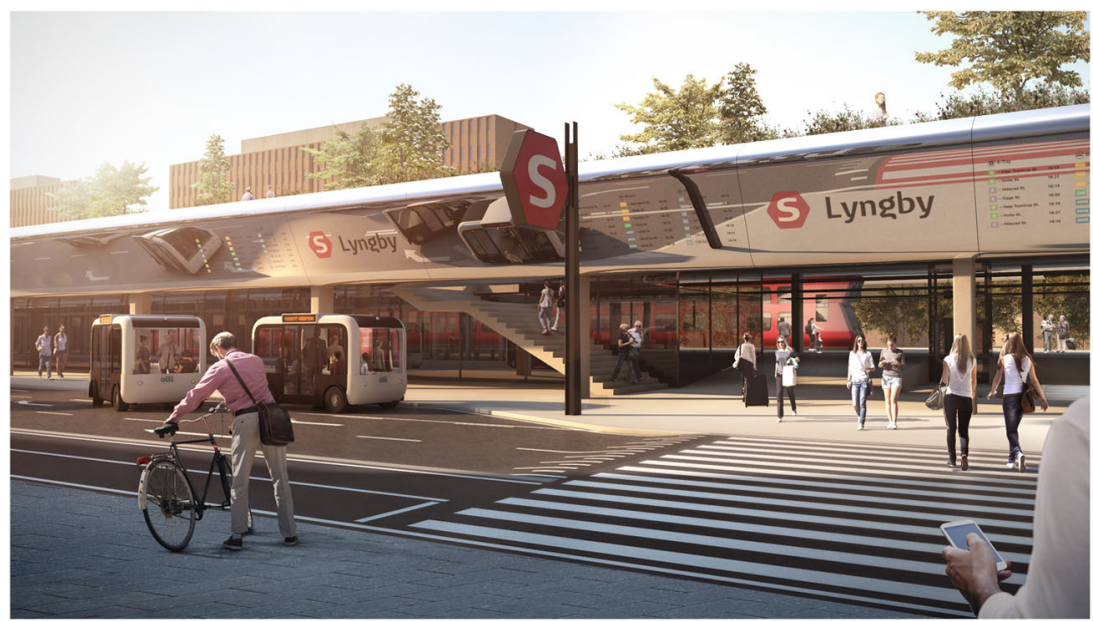

Fig. 7 CPH2050: From train station to mobility hub. This figure is not covered by the Creative Commons Attribution 4.0 International License. Reproduced with permission of JAJA (2018); copyright (c) JAJA Architects, all rights reserved.

Daimler, these depictions are not fixed, but co-evolve along with other system pressures. However, while the content within the image changes, the sociotechnical imaginary of a car-based society fundamentally remains the same. For Daimler, engaging with landscape pressures and emerging niches merely becomes an exercise in maintaining its own position within the system.

The analysis also shows that these companies' imaginaries would lead to different transition pathways and regime constellations, and therefore, the shaping of AV technology and society in the future. Thus, at the core of disseminating these depictions is the understanding that visualisations such as these are not neutral, and that the development of AV systems is not technologically determined, but the product of different actors' values. This is an important consideration, as Louise Reardon has already identified, is that discussions surrounding AVs have already been discursively depoliticised (Reardon, 2018). The entire idea of AVs is extremely politically optimistic with impatient politicians eagerly anticipating AVs as a package that can solve many of these most pressing challenges (ibid.).

This is most obvious in both companies' futures having a strong relationship to climate change and road safety discourses, although with large differences in approaches. As a legacy carmaker, Daimler presents a future where $\mathrm{CO}_{2}$ emissions and traffic safety accidents can simply be solved through the application of new technologies to the existing form of the car. The findings clearly demonstrate how Daimler frames AVs to stabilise their own position as regime actors through a business as usual' approach that suppresses other uses of AV technology. Daimler is first and foremost a vehicle manufacturer, and unlike other AV developers with backgrounds in tech, such as Apple and Google, who may be motivated through an increased market share of the attention economy (de Berker, 2017), Daimler's business model relies on it selling and leasing vehicles. There are too many inconsistencies in Daimler's presentations of the future, such as increasing amounts of road space, poorly designed bicycle infrastructure, and formal imitations of European public transport systems, to interpret their future literally. The company is locked into the system of automobility and their responses to ongoing landscape pressures are still framed around the car.

On the other JAJA's future is dominated by regime destabilisation. In an increasingly urbanised society, social, political, economic, technological, and digital systems are encroaching on each other's physical domains, and tensions are beginning to arise as space limitations force discussions on how that space should be allocated and used. JAJA's sociotechnical imaginary is based on the idea that shared AV use will lead to substantial urban renewal through the transformation of redundant road infrastructure (Duarte and Ratti, 2018). Instead of AVs becoming the dominant transportation mode, they will work as a supportive component in a broader system of multimodal transport. Through efficiency and appropriately sized vehicles, a total reduction in vehicle numbers could lead to previously used road space being transformed into new urban development, densification of suburban areas, and greater utilisation of public transport infrastructure. Just as Daimler tries to protect their business model through their framing of AVs, JAJA is expanding their business on their own.

The findings indicate the different approaches towards AVs from different system actors. It also demonstrates that if these visions become embedded in the dominant sociotechnical imaginary, they will play a major role in the shaping of assumptions of the role of AVs in the future. Moreover, the final constellation of regime actors and their ambitions will have implications for future sustainable transportation systems. However, the battle for the dominant sociotechnical imaginary should not be considered a negative process. Competition amongst actors from different system positions can increase the number of alternatives. By supporting pluralism, rather than focusing on minimising system deployment, AV developers and public authorities can open up new pathways for reconceptualising AV technology (Mladenović, 2019; Mladenović et al., 2020)

\section{Conclusions}

This paper aimed to analyse and discuss different imaginaries of AVs to understand their consequences for the future of transport systems and mobility. The paper particularly focused on how different system actors frame the role of AVs depending on their position within sociotechnical systems and their own business models. This was elaborated through a comparative analysis of AV futures visualisations from an incumbent regime actor, The Daimler Group, and an external system actor, JAJA Architects.

The concepts of a system of automobility, the MLP, and sociotechnical imaginaries shaped the theoretical background of the analytical framework. Combining them into a single framework enabled a deeper understanding of how depictions of AV futures are being framed, developed, and deployed, as well as their implications for future transition pathways and policy considerations. Although there have been historical criticisms of transition theory for a lack of explicit attention for the politics of technology that underpin the development and implementation of 
specific policies (Smith et al., 2005; Meadowcroft, 2011), more contemporary applications of the framework have expanded the MLP to include power and politics (Geels, 2014; Köhler et al., 2019). Transitions are deep-rooted political processes, in that different actors and groups will disagree about desirable outcomes and suitable ways in which to steer such a process. Furthermore, this process may lead to winners and losers: not only incumbent industries or new actors, but other user groups whose mobility access and opportunities may be reduced in alternative sociotechnical configurations such as the elderly, cyclists, or lower socio-economic communities. Thus, this specific contribution to the politics of AVs debate has been to conceptualise, identify and translate visual discursive material as instruments of regime stability or disruption over time.

When applying the analytical framework to the studied images, the analysis revealed that subsequent battles between niches and regimes take place on multiple landscape dimensions (e.g., sustainability, safety and infrastructure). Geels (2010) proposes that these struggles are not enacted by singular entities, but by numerous actors that "fight, negotiate, search, learn and build coalitions as they navigate transitions". This raises several different political-economy questions. Firstly, researchers and planners need to understand how collective actors may support different sociotechnical imaginaries. For example, an underlying challenge for advocates for shared AVs is the incumbent alliance between car manufacturers and governments. These alliances are built from mutual dependencies that see governmental revenue from car sales and fuel excises in exchange for favourable market conditions. Despite the impending challenge of climate change, without finding additional methods of raising revenue, governments may limit actions to transition towards more sustainable forms of AV use (Fishman, 2018), preferring to incorporate AV futures that replicate existing car systems and revenue streams. JAJA's visualisations (Fig. 4.) outline possible trajectories to counteract this mutual dependency. By engaging with liveability discourses, which centre around urban re-development, gentrification, and economic prosperity, JAJA offers a counterproposal to governments fixated on automobility tax revenues.

In addition, planners and policymakers should move beyond trying to anticipate AV futures towards actively asking what they want to achieve with them (Marsden, 2018). While they focus on the implications of possible trajectories, companies such as Daimler and JAJA are creating sociotechnical imaginaries of futures they are trying to create. I acknowledge that planners face a raft of challenges in determining their role in the development of AVs (Reardon, 2018), but I believe they also bring a valuable spatial perspective that can focus the deployment of AVs to solve existing challenges (Harris, 2018). Furthermore, when considering the long-term transition towards AVs, it is critical to reflect on which challenges could be implemented irrespective of automation and which challenges need further investigation. Possible methodologies could involve collaborative design experiments between governments and companies that utilise the same visualisation techniques outlined within this paper but are integrated within the context of local development goals (Martin et al., 2021).

In summary, the paper contributes to the literature by providing a critical examination of AV imaginaries in praxis. The findings also suggest that a more nuanced approach to reading $\mathrm{AV}$ visualisations requires moving beyond denotative readings to unpack the latent meanings alongside the broader context of automobility, landscape pressures, and parallel niche innovations. The work enriches the ability of academics and policymakers to understand the latent implications behind visual depictions of AVs over time through visual discourse analysis tools. However, the study is limited to data that was sourced between the years 2015-2018. In the following years, there have been a wide number of landscape shifts and new technologies. Therefore, an important subject for future research would include an analysis of AV futures since the beginning of the COVID-19 pandemic. An assumption could be that signifiers relating to sharing, and sustainability are replaced by ones communicating sterility, and private ownership. It would be important to identify this early so that policymakers do not unravel important steps towards the development of sustainable transportation systems in an effort to contain the SARSCOV-2 virus. Finally, although the study mainly focused on the visual analysis of imaginaries, further research could focus on the effect of sociotechnical imaginaries in praxis (e.g., whether they affect policymakers' decision-making processes or if the image's author is aware of the system it is depicting). This could involve investigating the site where sociotechnical imaginaries are disseminated to show how power relations give a greater advantage to certain actors in the marketplace of $\mathrm{AV}$ visions of the future.

\section{Data availability}

Some of the datasets generated during this study are included in this published study. Some of the specific datasets generated during this study are not publicly available as they form part of the author's ongoing Ph.D. research. They are available from the author on reasonable request.

Received: 25 May 2020; Accepted: 10 February 2021; Published online: 09 March 2021

\section{References}

Adams J (1999) The Social Implications of Hypermobility. Speculations about the Social Consequences of the OECD Scenarios for Environmentally Sustainable Transport and Business-as-Usual Trend Projections. Paris

Albers P (2013) Visual discourse analysis. In: New Methods of Literacy Research. pp. $85-97$

de Berker A (2017) Driverless Cars and the Attention Economy, Medium. https:// becominghuman.ai/driverless-cars-and-the-attention-economy-7efd6aa6a6a0 (Accessed 24 Sep 2020)

Blyth P, Mladenovic MN, Nardi BA, Ekbia HR, Su NM (2016) Expanding the design horizon for self-driving vehicles. IEEE Technol Soc Magazine 35:44-49

Bonnefon J-F, Černy D, Danaher J, Devillier N, Johansson V, Kovacikova T, Martens M, Mladenovic M, Palade P, Reed N, Santoni de Sio F (2020) Ethics of connected and Automated Vehicles. Luxembourg https://doi.org/10.2777/966923

Burke K (2019) How Does a Self-Driving Car See?, NVIDIA. https://blogs.nvidia. com/blog/2019/04/15/how-does-a-self-driving-carsee/\#: :text=Camera\%2C \%20radar\%20and\%20lidar\%20sensors\%20give\%20autonomous\%20vehicles\% 20superhuman\%20vision.\&text=By\%20combining\%20a\%20variety\%20of, even $\% 20$ better\%20than $\% 20$ human\%20eyesigh radar and lidar sensors give autonomous vehicles superhuman vision.\&text $=$ By combining a variety of, even better than human eyesight. (Accessed 14 Jan 2021)

Cavoli C, Phillips B, Cohen T, Jones P (2017) Social and behavioural questions associated with automated vehicles: a literature review, (January), p. 124. https:// www.gov.uk/government/publications/social-and-behavioural-questionsassociated-with-automated-vehicles\%0A, https://rid.trb.org/view/1457834

Cheney-Lippold J (2019) Accidents happen. Soc Res 86(2):513-536

Cohen T, Cavoli C (2019) Automated vehicles: exploring possible consequences of government (non)intervention for congestion and accessibility. Transp Rev 39(1):129-151. https://doi.org/10.1080/01441647.2018.1524401

Conley J (2009) Car troubles: critical studies of automobility and auto-mobility. Taylor \& Francis, London, McLaren AT (ed)

Duarte F, Ratti C (2018) The impact of autonomous vehicles on cities: a review. J Urban Technol 0732. https://doi.org/10.1080/10630732.2018.1493883

Fishman E (2018) Autonomous vehicles: opportunities, challenges and the need for government action. Plann Theory Practice 19(5):764-767

Fraedrich E, Beiker S, Lenz B (2015) Transition pathways to fully automated driving and its implications for the sociotechnical system of automobility. Eur J Futures Res 3(1). https://doi.org/10.1007/s40309-015-0067-8

Freudendal-Pedersen M, Hannam K, Kesselring S (2016) Applied mobilities, transitions and opportunities. Appl Mobilit 1(1):1-9. https://doi.org/10.1080/ 23800127.2016.1150562

Ganesh MI (2020) The ironies of autonomy. Humanit Soc Sci Commun 7(1):1-10. https://doi.org/10.1057/s41599-020-00646-0

Gee JP (2006) An introduction to discourse analysis: theory and method, 2nd edn. Routledge, London, https://doi.org/10.1177/146144560600800308 
Geels F (2010) Ontologies, socio-technical transitions (to sustainability), and the multi-level perspective. Res Policy 39:495-510. https://doi.org/10.1016/j. respol.2010.01.022

Geels F, Schot J (2010) The Dynamics of Transitions: A Socio-Technical Perspective. In: Grin, J, Rotmans J, Schot J (eds) Transitions to Sustainable Development: New Directions in the Study of Long Term Transformative Change. 1st edn. Routledge, pp. 11-102

Geels FW (2005) The dynamics of transitions in socio-technical systems: a multilevel analysis of the transition pathway from horse-drawn carriages to automobiles (1860-1930). Technol Anal Strateg Manag 17(4):445-476. https://doi.org/10.1080/09537320500357319

Geels FW (2012) A socio-technical analysis of low-carbon transitions: introducing the multi-level perspective into transport studies. J Transp Geogr 24:471-482. https://doi.org/10.1016/j.jtrangeo.2012.01.021

Geels FW (2014) Regime resistance against low-carbon transitions: introducing politics and power into the multi-level perspective. Theory Cult Soc 31 (5):21-40. https://doi.org/10.1177/0263276414531627

Goodwin P (1995) Car dependence. Transp Policy https://doi.org/10.1016/0967070X(95)96744-6

Hajer M, Versteeg W (2019) Imagining the post-fossil city: why is it so difficult to think of new possible worlds? Territory Politics Governance 7(2):122-134. https://doi.org/10.1080/21622671.2018.1510339

Harris J (2018) Autonomous vehicles - a planner's response. Plann Theory Practice 19:5

Hodge R, Kress G (1988) Social semiotics. Polity Press, Cambridge

Hodson M, Geels F, Mcmeekin A (2015) 'Land-based passenger mobility system'. (603942).

Jacobs S (2014) Cities that score well barely qualify as cities, dezeen. https://www. dezeen.com/2014/09/04/sam-jacob-opinion-city-rankings-flawed-way-tojudge-best-cities-in-the-world/

Jasanoff S (2015) Future imperfect: science, technology, and the imaginations of modernity. In:Jasanoff S, Kim S-H (eds) Dreamscapes of modernity: sociotechnical imaginaries and the fabrication of power. University of Chicago, Chicago, p. 341

Jasanoff S, Kim SH (2009) Containing the atom: sociotechnical imaginaries and nuclear power in the United States and South Korea. Minerva 47(2):119-146. http://www.jstor.org/stable/41821489

Jewitt C, Oyama R (2011) Visual meaning: a social semiotic approach. Handbook Vis Anal 135:156

Kaiserfeld T (2007) Born to run or chained to the car? American vs European visions and practices of automobile society. Royal Institute of Technology, Stockholm, Sweden, pp. 1-12

Kim ES (2018) Sociotechnical imaginaries and the globalization of converging technology policy: technological developmentalism in South Korea. Sci Culture 27(2):175-197. https://doi.org/10.1080/09505431.2017.1354844

Köhler J (2019) An agenda for sustainability transitions research: State of the art and future directions. Environ Innovat Societ Trans https://doi.org/10.1016/j. eist.2019.01.004.

Kornhauser AL (2013) Smart driving cars: history and evolution of automated vehicles. Florida Automated Vehicles Summit

Kress G, van Leeuwen T (2006) Reading images: the grammar of visual design, 2nd edn. Taylor \& Francis Routledge, London

Lamon P, Kolski S, Siegwart R (2006) The SmartTer-a vehicle for fully autonomous navigation and mapping in outdoor environments. In: 9th International Conference on Climbing and Walking Robots and the Support Technologies for Mobile Machines, (January)

Lyons G (2015) Transport's digital age transition. J Transport Land Use 8(2):1-19. http://www.jstor.org/stable/26202710

Mackinnon D, Pririe G, Gather M (2008) 'Transport and economic development'. In:Knowles RD, Shaw J, Docherty I (eds) Transport Geographies: Mobilities, Flows and Spaces. Blackwell, Oxford, pp. 10-28

Marsden G (2018) Planning for autonomous vechiles? Questions of purpose, place and pace. Plann Theory Practice 19:5

Martin R, Bruck EM, Soteropoulos A (2021) Transformations of European Public Spaces with AVs (In Print). In:Mitteregge M, et al., (eds) AVENUE21 Volume 2: Policy and Planning Considerations for Automated Mobility. Springer Vieweg, Heidelberg

McArthur J, Robin E (2019) Victims of their own (definition of) success: Urban discourse and expert knowledge production in the Liveable City. Urban Stud 56(9):1711-1728. https://doi.org/10.1177/0042098018804759

McNeil MC et al. (2017) Conceptualizing imaginaries of science, technology, and society. In:Felt U, et al. (eds) The Handbook of Science and Technology Studies. MIT Press, Cambridge, pp. 435-464

Meadowcroft J (2011) Engaging with the politics of sustainability transitions. Environmental Innovation and Societal Transitions. https://doi.org/10.1016/j. eist.2011.02.003

Milakis D, Van Arem B, Van Wee B (2017) Policy and society related implications of automated driving: a review of literature and directions for future research. J Intell Transport Syst 21(4):324-348. https://doi.org/ $10.1080 / 15472450.2017 .1291351$

Mladenović MN (2019) How Should We Drive Self-driving Vehicles? Anticipation and Collective Imagination in Planning Mobility Futures, 103-122. https:// doi.org/10.1007/978-3-319-96526-0_6

Mladenović MN, Stead D, Milakis D, Pangbourne K, Givoni M (2020) Governance Cultures and Sociotechnical Imaginaries of Self- Driving Vehicle Technology: Comparative Analysis of Finland, UK and Germany. In: Milakis D, Thomopoulos, N, van Wee B (eds) Advances in Transport Planning and Policy. Academic Press. pp. 235-262

Mom G (2014) Atlantic Automobilism: Emergence and Persistence of the Car 1895-1940. Berghahn Books

Moradi A, Vagnoni E (2018) A multi-level perspective analysis of urban mobility system dynamics: what are the future transition pathways? Technol Forecast Soc Change 126:231-243. https://doi.org/10.1016/j.techfore.2017.09.002

Norton PD (2007) Street rivals: Jaywalking and the invention of the motor age street. Technol Culture 48(2):331-359. https://doi.org/10.1353/tech.2007.0085

Norton PD (2010) Fighting traffic: the dawn of the motor age in the American city. J Am Hist https://doi.org/10.2307/27694848

Pattinson JA, Chen H, Basu S (2020) Legal issues in automated vehicles: critically considering the potential role of consent and interactive digital interfaces Humanit Soc Sci Commun 7(1):1-10. https://doi.org/10.1057/s41599-020-00644-2

Reardon L (2018) Ensuring good governance: the role of planners in the development of autonomous vehicles. Plann Theory Practice 19(5):773-776

Rose G (2010) Visual methodologies. an introduction to the interpretation of visual materials, 2nd edn. SAGE Publications, London, 10.5212/Rlagg.v.3.i2.178180

Sadowski J, Bendor R (2018) Selling smartness: corporate narratives and the smart city as a sociotechnical imaginary. Sci Technol Human Values https://doi.org/ $10.1177 / 0162243918806061$

SAE International (2018) Taxonomy and Definitions for Terms Related to Driving Automation Systems for On-Road Motor Vehicles

Sage A (2016) Where's the lane? Self-driving cars confused by shabby U.S roadways, Reuters. https://www.reuters.com/article/us-autos-autonomousinfrastructure-insig/wheres-the-lane-self-driving-cars-confused-by-shabbyu-s-roadways-idUSKCNOWX131 (Accessed 18 Jan 2021)

Sheller M (2004) Automotive emotions: feeling the car. Theory Cult Soc 21 (5):221-242. https://doi.org/10.1177/0263276404046068

Simpson D (ed.) (2018) Atlas of the Copenhagens. Ruby Press, Berlin

Smith A, Stirling A, Berkhout F (2005) The governance of sustainable sociotechnical transitions. Res Policy https://doi.org/10.1016/j.respol.2005.07.005

Soteropoulos A, Berger M, Ciari F (2019) Impacts of automated vehicles on travel behaviour and land use: an international review of modelling studies. Transp Rev 39(1):29-49. https://doi.org/10.1080/01441647.2018.1523253

Stayton E, Stilgoe J (2020) It's time to rethink levels of automation for selfdriving vehicles. SSRN Electronic J 2019(2016):391-397. https://doi.org/ $10.2139 /$ ssrn. 3579386

Stilgoe J (2017) Seeing like a Tesla: how can we anticipate self-driving worlds?, J Cult 3. https://doi.org/10.12893/gjcpi.2017.3.2

Stilgoe J (2018) Machine learning, social learning and the governance of self-driving cars. Soc Stud Sci 48(1):25-56. https://doi.org/10.1177/0306312717741687

Stradling SG, Meadows ML, Beatty S (2000) Helping drivers out of their cars integrating transport policy and social psychology for sustainable change. Transp Policy 7(3):207-215. https://doi.org/10.1016/S0967-070X(00)00026-3

Taiebat $\mathrm{M}$ et al. (2018) A review on energy, environmental, and sustainability implications of connected and automated vehicles. Environ Sci Technol 52 (20):11449-11465. https://doi.org/10.1021/acs.est.8b00127

Turnheim B et al. (2015) Evaluating sustainability transitions pathways: bridging analytical approaches to address governance challenges. Global Environ Change 35(2015):239-253. https://doi.org/10.1016/.j.gloenvcha.2015.08.010

United Nations Department of Economic and Social Affairs (2019) World Urbanization Prospects: The 2018 Revision. New York

Urry J (2005) The "System" of Automobility. In: Automobilities. SAGE Publications, London. pp. 25-40

Vigar G (2013) The Politics of Mobility. Polit Mobility https://doi.org/10.4324/ 9780203857557

Wetmore J (2003) Driving the dream-the history and motivations behind 60 years of automated highway systems in America. Automat Hist Rev 4:19

World Health Organization (2018) Global Status Report on Road, World Health Organization, 20

Zijlstra T, Avelino F (2012) A socio-spatial perspective on the car regime. In:Geels FW, et al. (eds) Automobility in Transition? A Socio-Technial Analysis of Sustainable Transport. Routledge, New York, p. 373

\section{Acknowledgements}

The author wishes to thank the Innovation Fund Denmark and JAJA Architects for their generous financial support under the Industrial Ph.D. Programme. The author would also like to thank Daimler Global Media and JAJA Architects for providing visual material for this 
paper. Finally, the author would like to thank the ongoing support of his Ph.D. supervisor, Malene Freudendal-Pedersen, for her guidance throughout the preparation of this paper.

\section{Competing interests}

The author is employed as an Industrial Ph.D. Researcher by JAJA Architects.

\section{Additional information}

Correspondence and requests for materials should be addressed to R.M.

Reprints and permission information is available at http://www.nature.com/reprints

Publisher's note Springer Nature remains neutral with regard to jurisdictional claims in published maps and institutional affiliations. (c) (i) Open Access This article is licensed under a Creative Commons Attribution 4.0 International License, which permits use, sharing, adaptation, distribution and reproduction in any medium or format, as long as you give appropriate credit to the original author(s) and the source, provide a link to the Creative Commons license, and indicate if changes were made. The images or other third party material in this article are included in the article's Creative Commons license, unless indicated otherwise in a credit line to the material. If material is not included in the article's Creative Commons license and your intended use is not permitted by statutory regulation or exceeds the permitted use, you will need to obtain permission directly from the copyright holder. To view a copy of this license, visit http://creativecommons.org/ licenses/by/4.0/.

(C) The Author(s) 2021 